\title{
Laparoscopic Nephropexy Exposes a Possible Underlying Pathogenic Mechanism and Allows Successful Treatment with Tissue Gluing of the Kidney and Fixation of the Colon to the Lateral Abdominal Wall
}

\author{
Jonas Wadstrom, Michael Haggman
}

Department of Surgical Sciences, Uppsala University Hospital, Uppsala, Sweden

\begin{abstract}
Objectives: Surgical treatment of "Ren Mobilis" has historically been associated with poor results and fairly high morbidity. We have used a transperitoneal laparoscopic approach in order to minimize morbidity. The goal of this study was to evaluate the success rate and to discuss the possible pathogenic mechanism, which has implications for the surgical strategy.

Materials and Methods: Seven women with a right mobile kidney were examined by intravenous pyelogram and CT scans. Symptoms were judged to emanate from the mobile kidney. Transperitoneal laparoscopic nephropexy was performed. The surgical treatment consisted of fixing the kidney to the dorsal abdominal wall using tissue glue (Tisseel ${ }^{\circledR}$ ) after diathermy coagulation of the surfaces to induce fibrosis. The right colon was fixed with clips to the lateral abdominal wall, trapping the kidney in place.

Results: In 6 of the cases, there was an incomplete rotation of the ascending colon to the right side, allowing the kidney to move freely. In one case, the kidney moved into a retroperitoneal pocket of the mesocolon. The 6 cases with a lateral passage for the kidney were symptom-free at follow-up (30-80 months), but in the 7th case the patient's kidney quickly loosened and she underwent an open reoperation, after which she was symptom-free.

Conclusion: Our series demonstrates that good results can be achieved with a transperitoneal laparoscopic approach, but also indicates that there is a common pathogenic mechanism with incomplete rotation of the ascending colon that can be corrected during surgery, which might contribute to the good results.
\end{abstract}

Key words: kidney; ptosis; pathology; laparoscopic surgery

Int Braz J Urol. 2010; 36: 10-7

\section{INTRODUCTION}

The general definition of "Ren Mobilis" (nephroptosis) is that the kidney descends two vertebral bodies or $5 \mathrm{~cm}$ when the body posture changes from supine to an upright position. Surgical treatment of nephroptosis by fixation or suspension of the kidney has been performed since Hahn's first report in
1881 (1). Numerous surgical techniques have been described since, but the success rate has been low and the procedures have been associated with fairly significant morbidity. The procedures were therefore almost abandoned for many years but with the introduction of refined diagnostic tools and minimally invasive surgery the diagnosis and surgical treatment of nephroptosis has received renewed interest. Indeed, 
there are several reports today of successful laparoscopic nephropexy with low morbidity (2-6).

These reports have all focused on modalities for fixation of the kidney by sutures, vaginal tape or gluing, etc. In the present report, we describe a new a possibly pathogenic mechanism behind the condition and a causal therapy of a combination of fixation of the kidney in its normal anatomical position and attachment of the right colon to the lateral abdominal wall. The latter appears to be important since we found that in all cases there was malrotation or a long mesocolon that allowed the kidney to move freely in a medial and caudal direction.

\section{MATERIALS AND METHODS}

\section{Patient Demographics}

Between 1998 and 2004, 7 women, 19 to 57 years old (mean age 33), were referred to our department for surgery of a mobile kidney. All had right-sided symptoms and preoperative work-up with intravenous pyelography and CT scan showed a mobile right kidney, Figure-1. None of the patients had any previous history of urinary tract infections, hypertension or renal calculi. Patient characteristics are given in Table-1.

\section{Laparoscopic Surgical Technique}

The patients were positioned in a semi-lateral position with 45-degree rotation. A transperitoneal approach was used for the procedure. Three $12 \mathrm{~mm}$ ports were placed in the anterior axillary line and one in the flank.

With the patient rotated 45 degrees, it was evident in all cases that there was an incomplete intestinal rotation so that the right colon was flexed medially and the entire kidney was immediately visible. The kidney was also freely movable in a medial and caudal direction. The operation starts with incision of the posterior peritoneum without having to incise the line of Toldt. The ureter is identified and the perirenal fat dissected and the kidney completely mobilized.
Gerota's fascia was in most cases underdeveloped or absent. The posterior renal capsule was superficially cauterized to induce postoperative scarring. The fatty tissue of the posterior renal bed was treated in the same manner. A high viscosity fibrin sealant (TisseelDuo Quick ${ }^{\circledR}$, Baxter AG, Vienna, Austria) with prolonged setting time was prepared by mixing the fibrinogen component with hyaluronic acid (Healon ${ }^{\circledR}$, Advanced Medical Optics, Inc., Santa
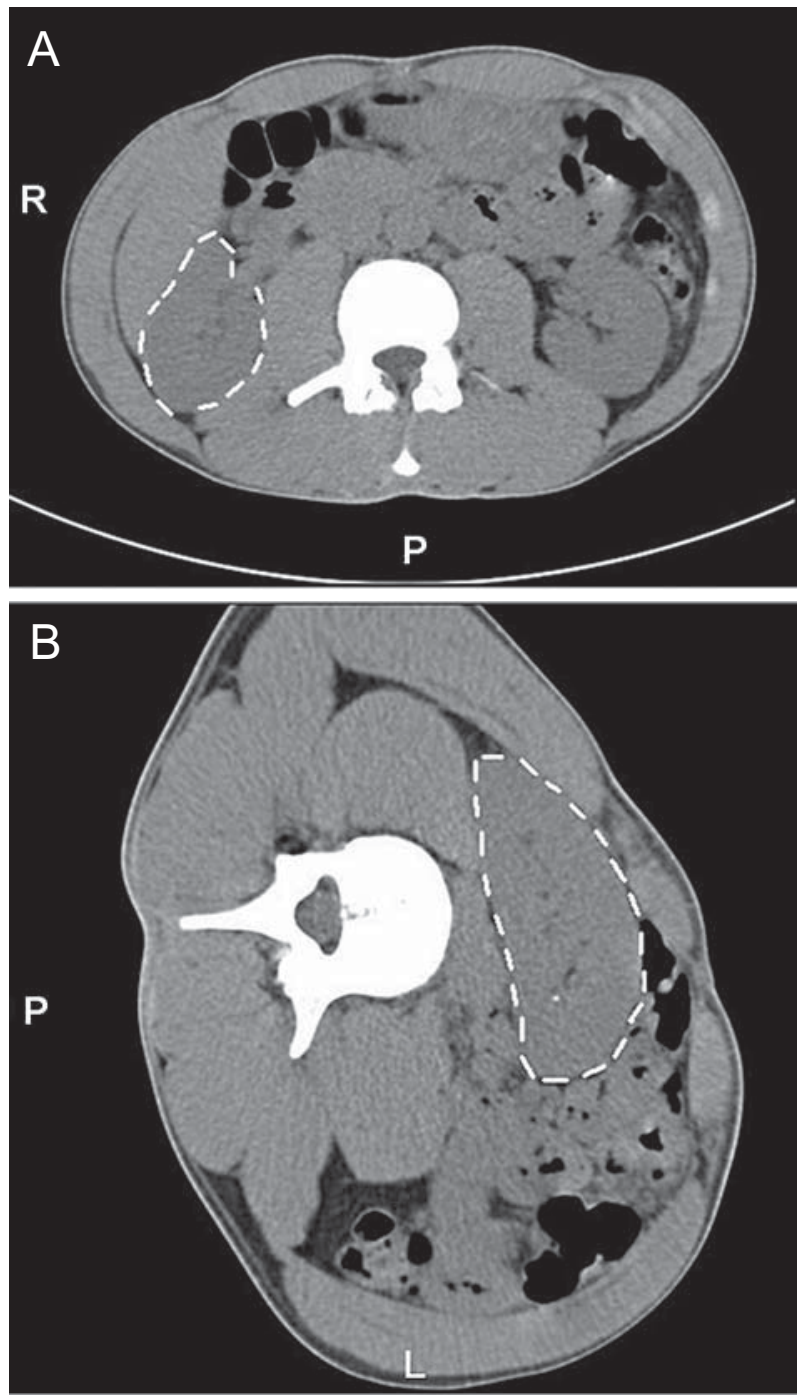

Figure 1 - A) CT-scan in supine position, depicting both kidneys in normal anatomical position. B) CT-scan in left lateral position, depicting the left kidney now flipped medially and in a caudal direction (right kidney no longer visible). 
Table 1 - Patient characteristics.

\begin{tabular}{lcccccccccc}
\hline Case N. & Age & Pain & BMI & Parity & IVP & US & CT scan & $\begin{array}{c}\text { Double-J } \\
\text { Stent }\end{array}$ & $\begin{array}{c}\text { Palpable } \\
\text { Mass }\end{array}$ \\
\hline 1 & 19 & Yes & 23.2 & 0 & Pos & ND & Pos & ND & Yes \\
2 & 27 & Yes & 26.3 & 0 & Pos & Pos & Pos & ND & Yes \\
3 & 32 & Yes & 20.4 & 4 & Pos & Pos & Pos & Neg & Yes \\
4 & 33 & Yes & 20.1 & 3 & Pos & Pos & ND & Pos & Yes \\
5 & 33 & Yes & 20.5 & 4 & Pos & Pos & Pos & ND & Yes \\
6 & 37 & Yes & 23.6 & 2 & Pos & Pos & Pos & ND & Yes \\
7 & 48 & Yes & 22.3 & 2 & Pos & Pos & ND & ND & Yes \\
\hline
\end{tabular}

$B M I=$ body mass index; IVP= intravenous pyelography; US = ultrasound; $C T=$ computed tomography; Pos = finding of mobile kidney confirmed; Neg = mobile kidney not confirmed; $N D=$ not done

Ana, CA) at a ratio of $1: 1$. The thrombin component was diluted with saline to reach a concentration of $40 \mathrm{U} / \mathrm{mL}$. A final total volume of $4 \mathrm{~mL}$ was applied to the posterior renal bed with an application catheter (Duplocath ${ }^{\circledR}$, Baxter AG, Vienna, Austria). The high viscosity combined with a prolonged setting time allowed sufficient time to reposition the kidney without glue running off or instantaneous setting of the glue. The kidney was then compressed to the posterior bed for 5 minutes allowing the glue to set. After the kidney had been secured in its anatomically correct position, the colon was attached to the lateral abdominal wall and the right flexure to cover the kidney under the right liver lobe. Fixation was achieved with clips (Endopath ${ }^{\circledR}$ EMS, Ethicon, Cincinnati, USA).

The intraoperative situs is depicted in Figure2A and B. A schematic drawing of intraoperative situs before and after fixation of the right colon to the lateral wall is depicted in Figure-3.

Before allowing the patient to wake up after surgery, a girdle was applied to the lower half of the abdomen to prevent the kidney from sliding in a caudal direction.

Postoperatively the patients had bed rest for 24 hours to allow initial scarring and fixation without subjecting the kidney to gravitational forces. They were allowed oral feeding immediately.

Patients were followed up in the clinic 2-3 months postoperatively and then by phone $1-4$ years after their procedure.
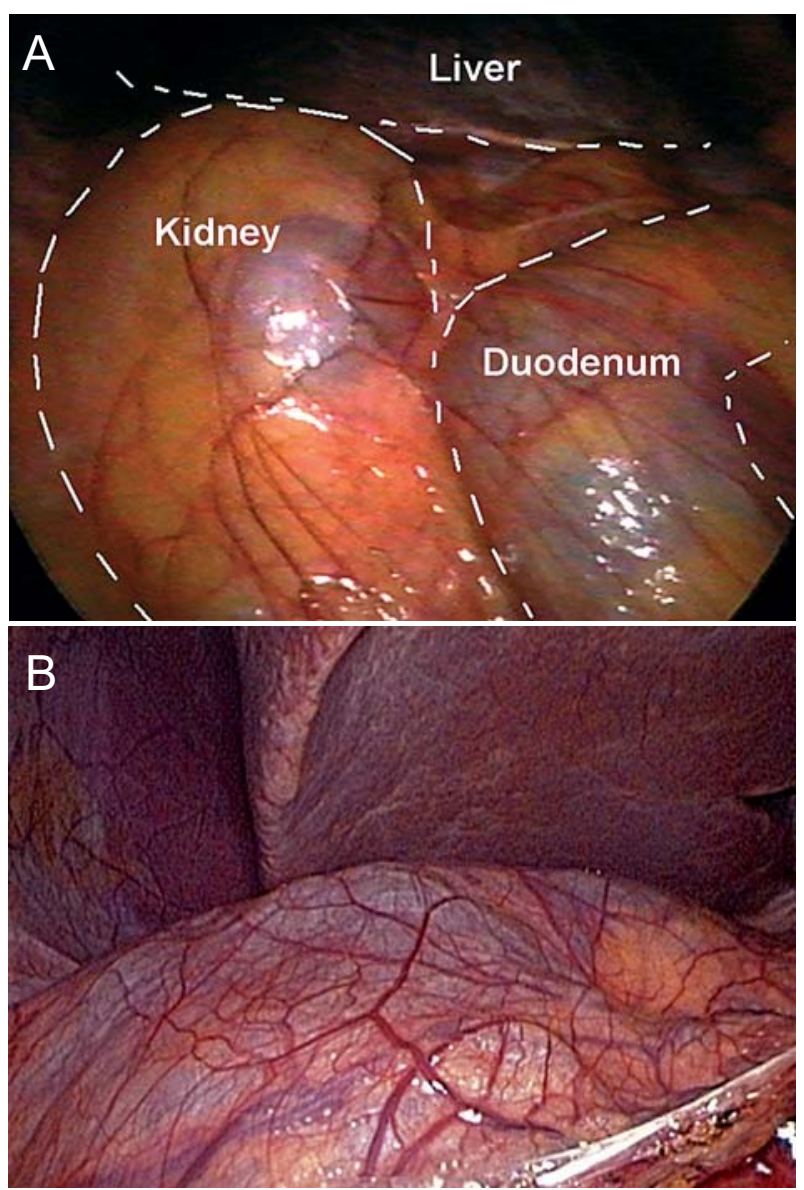

Figure $2-A$ ) Laparoscopic view at beginning of procedure. Right kidney (left) and duodenum (right). Ascending colon further to right, out of picture. B) Laparoscopic view at beginning of procedure from another patient demonstrating a thin Gerota's fascia covering the right kidney. In the lower left corner is the right flexure of the colon. 

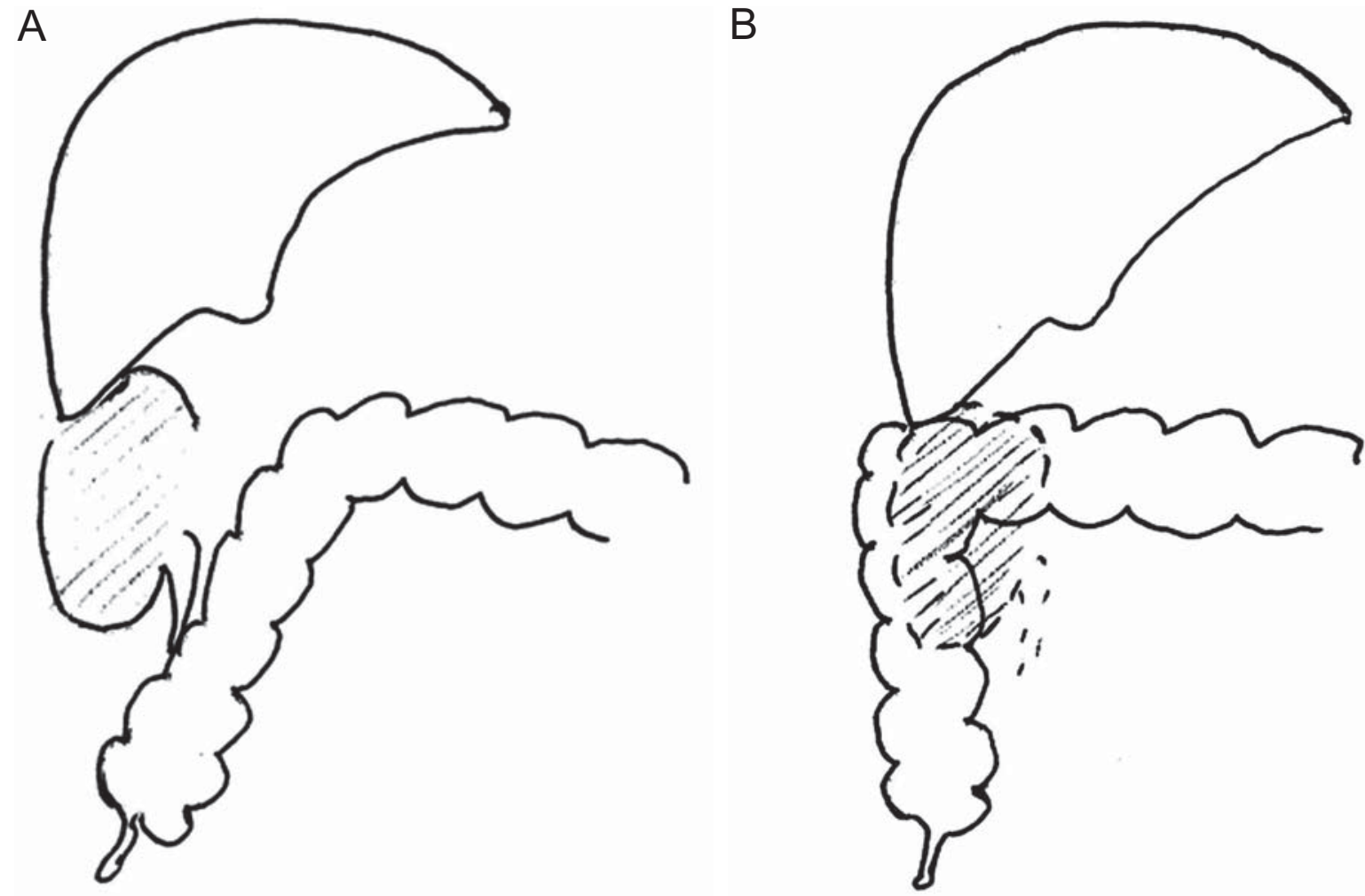

Figure 3 - A) and B) A schematic drawing of intraoperative situation before and after fixation of the right colon to the lateral wall.

\section{RESULTS}

Mean operative time was 142 min. (100-145). In all cases, the immediate postoperative course was uneventful, notably, no thromboembolic complications occurred in spite of the 24 hours of bed rest in the dorsal position. Postoperative hospitalization was 3.6 days (3-4), including 1 day of bed rest.

The 6 cases with a lateral passage for the kidney were symptom-free at follow-up, but in the 7 th case the patient's kidney quickly loosened and she underwent an open reoperation, this time securing the kidney with traditional suturing in a retroperitoneal pocket, after which no further symptoms occurred. Telephone follow-up at 30-80 months postoperatively revealed no further symptoms associated with the kidney in the operated cases, though the patient who was reoperated with an open procedure has had some scar-related problems in the flank incision. Interestingly, one patient had complete relief of previous constipation after her procedure. The postoperative course is summarized in Table-2.

\section{COMMENTS}

In recent years, surgical treatment of nephoptosis has received renewed interest and laparoscopic and retroperitoneoscopic techniques have been advocated (2-13).

In these studies, treatment has in most cases been successful with low surgical morbidity. Fixation of the kidney has been achieved predominantly by suturing of the capsule to the posterior abdominal wall. However, none of the studies have tried to analyze and treat a pathogenic cause. Already in our first case, it was evident that there was an incomplete rotation of the ascending colon. The colon was not attached to the posterior-lateral abdominal wall. This allowed direct visualization of the kidney without 
Table 2-Postoperative course.

\begin{tabular}{lcccc}
\hline Case N. & $\begin{array}{c}\text { Operative Time } \\
(\text { min. })\end{array}$ & $\begin{array}{c}\text { Postoperative } \\
\text { Hospital Stay }\end{array}$ & $\begin{array}{c}\text { Intraoperative } \\
\text { Finding }\end{array}$ & $\begin{array}{c}\text { Reoperation/ } \\
\text { Complication }\end{array}$ \\
\hline 1 & 105 & 3 days & Incomplete rotation & No \\
2 & 100 & 3 days & Incomplete rotation & No \\
3 & 115 & 4 days & Incomplete rotation & No \\
4 & 145 & 4 days & Incomplete rotation & Yes, open nephropexy \\
5 & $145+175$ & $6+4$ days & Retrocolic pocket & No \\
7 & 120 & 4 days & Incomplete rotation & No \\
\hline
\end{tabular}

loosening the colon from the lateral abdominal wall. There was a long and loose right mesocolon and the right flexure was freely movable to the left side of the abdomen. In addition, Gerota's fascia was weak or missing. This allowed the kidney to move freely in a caudal and medial direction (Figure-1). We therefore decided intraoperatively not only to fix the kidney in its anatomical location, but also to attach the colon to the lateral abdominal wall and the right flexure so that it covered the kidney below the right lobe of the liver (Figure-3). The same anatomical variant was then found in all subsequent cases but one.

Instead of fixating the kidney with sutures, we tried to induce scarring by treating the posterior capsule of the kidney and the fatty tissue of the renal bed using cautery. To temporarily hold the kidney in position, we used a viscosity-enhanced fibrin sealant with a prolonged setting time. This allowed sufficient time to turn the kidney back into its anatomical position before the glue ran off or started to set. We believe the gluing is preferable to suturing since it is sometimes difficult to suture without risking injury of the kidney or the ilio-hypogastric or genitofemoral nerves. None of our patients had any neuralgia, which is not an uncommon finding when sutures are used (14). An alternative method could be to use polymer clips if the perirenal fat and tissue is strong. This would lower costs (15).

Fibrin sealants are absorbed and lose their strength in a fairly short time. The scarring induced by cauterization of the renal capsule and the fatty tissue of the renal bed is unlikely to be strong enough to hold the kidney in its anatomical position. We therefore believe that attaching the right colon to the lateral abdominal wall and covering the kidney with the right flexure of the colon is an essential part of a successful treatment approach. This view is further supported by the interoperative finding that insufficient rotation of the colon appears to be an underlying pathogenic mechanism for nephroptosis.

Most previous open surgical techniques for the treatment of nephroptosis and most of the minimally invasive techniques have been performed by a retroperitoneal approach (7-13). The presently proposed pathogenic mechanism is not revealed and cannot be corrected with a retroperitoneal approach and could thus be an explanation for the poor results in the past. None of the authors who have used a transperitoneal technique have mentioned the finding of an incomplete rotation of the colon (2-6). It should, however, be noted that Hübner and Plas $(4,5)$ offer the following description: "Owing to the absence of the fatty capsular tissue, the kidney was easily identified", a condition, which is very similar to what we describe in Figure-1. In describing the operative procedure, they do not mention mobilizing the colon but rather add that, directly after creating the pneumoperitoneum: "The kidney [is] easily identified. The peritoneum and Gerota's fascia are opened in a T-shaped incision." Fornara et al. (6) give the following description: "The line of Toldt was incised and the ureter was identified. The perirenal fat was then dissected and the kidney was completely mobilized." The authors do not describe the necessity of 
mobilizing the ascending colon. It is thus possible that the previous authors who used a transperitoneal technique also encountered an incomplete rotation of the ascending colon but did not realize that it could be a contributing pathogenic mechanism. A further indication that there is a common pathogenic mechanism is the intriguing fact that the condition is almost always on the right side. It is also of interest to note that Curtis et al. (16) have demonstrated that in cases of renal ectopia the distal ascending colon is visualized medial to the anterior part of the right colonic flexure and proximal to the transverse colon. These authors relate this finding to the fact that during fetal development a normal ascent and fixation of the kidney is necessary for the formation of the perirenal fascia and that this process is intimately associated with the formation of extraperitoneal fascial planes and colonic supporting structures. Cases are also described where there is a malrotation of the left colon, which is associated with a left-sided pelvic kidney (17). There are thus several pieces of circumstantial evidence indicating that incomplete rotation of the colon plays a pathogenic role in "Ren Mobilis" and that fixation of the colon in its correct anatomical position is of advantage in order to achieve an optimal surgical result.

\section{CONCLUSION}

Surgical treatment for nephroptosis should only be considered after a careful and cautious preoperative evaluation. The findings of our present study, however, indicate that a transperitoneal laparoscopic approach can give good results with a low morbidity and allow correction for a possible pathogenic mechanism underlying the condition. If the results can be confirmed in larger studies, this might lead to renewed interest in the condition and offer better treatment options for a number of patients currently dissuaded from surgical treatment.

\section{ACKNOWLEDGEMENT}

Funding for this study was received from Uppsala University.

\section{CONFLICT OF INTEREST}

None declared.

\section{REFERENCES}

1. Barber NJ, Thompson PM: Nephroptosis and nephropexy--hung up on the past? Eur Urol. 2004; 46: 428-33.

2. Urban DA, Clayman RV, Kerbl K, Figenshau RS, McDougall EM: Laparoscopic nephropexy for symptomatic nephroptosis: initial case report. J Endourol. 1993; 7: 27-30.

3. Elashry OM, Nakada SY, McDougall EM, Clayman RV: Laparoscopic nephropexy: Washington University experience. J Urol. 1995; 154: 1655-9.

4. Hübner WA, Schramek P, Pflüger H: Laparoscopic nephropexy. J Urol. 1994; 152: 1184-7.

5. Plas E, Daha K, Riedl CR, Hübner WA, Pflüger H: Long-term followup after laparoscopic nephropexy for symptomatic nephroptosis. J Urol. 2001; 166 : 449-52.

6. Fornara P, Doehn C, Jocham D: Laparoscopic nephropexy: 3-year experience. J Urol. 1997; 158: 167983.

7. El-Moula MG, Izaki H, Kishimoto T, Takahashi M, Fukumori T, Kanayama HO: Laparoscopic nephropexy. J Laparoendosc Adv Surg Tech A. 2008; 18: 230-6.

8. Rassweiler JJ, Frede T, Recker F, Stock C, Seemann O, Alken P: Retroperitoneal laparoscopic nephropexy. Urol Clin North Am. 2001; 28: 137-44.

9. Wyler SF, Sulser T, Casella R, Hauri D, Bachmann A: Retroperitoneoscopic nephropexy for symptomatic nephroptosis using a modified three-point fixation technique. Urology. 2005; 66: 644-8.

10. Chueh SC, Hsieh JT, Chen J, Young YL, Chen SC, Tu YP: Retroperitoneoscopic nephropexy for symptomatic nephroptosis. Surg Endosc. 2002; 16: 1603-7.

11. Ichikawa T, Yamada D, Takao A, Saegusa M, Aramaki K, Kumon H: Retroperitoneoscopic nephropexy for symptomatic nephroptosis. J Endourol. 2003; 17: 767-70.

12. Matsui Y, Matsuta Y, Okubo K, Yoshimura K, Terai A, Arai Y: Laparoscopic nephropexy: treatment outcome and quality of life. Int J Urol. 2004; 11: 1-6.

13. Gözen AS, Rassweiler JJ, Neuwinger F, Bross S, Teber D, Alken P, et al.: Long-term outcome of laparoscopic retroperitoneal nephropexy. J Endourol. 2008; 22: 2263-7. 
14. Hagmaier V, Heberer M, Leibundgut B, Ferstl A, Buser $\mathrm{S}$, Schoenenberger GA, et al.: Long-term observations on different methods of nephropexy. Helv Chir Acta. 1979; 46: 351-5.

15. Tunc L, Yesil S, Guneri C, Biri H, Ure I, Bozkirli I: The use of polymer clips in transperitoneal laparoscopic nephropexy. Surg Laparosc Endosc Percutan Tech. 2008; 18: 124-6.

\section{Correspondence address:}

Dr. Jonas Wadström

Surgical Department

Rikshospitalet University Hospital

0027, Oslo, Norway

Fax: + 47 2307-0510

E-mail: jonas.wadstrom@rikshospitalet.no

\section{EDITORIAL COMMENT}

Ever since the existence of surgical therapy of nephroptosis it has always been a subject of discussion. A partly uncritical jubilation for surgery has led to the fact, that nephropexy was the most performed urological operation in the beginning of the 20th Century with up to 200 different operative variations. Laparoscopy has been reported recently as a minimally invasive approach for nephropexy. The article of Wadström and Häggman offers a new possible underlying pathogenic mechanism for the
16. Curtis JA, Sadhu V, Steiner RM: Malposition of the colon in right renal agenesis, ectopia, and anterior nephrectomy. AJR Am J Roentgenol. 1977; 129: 84550.

17. Vanmuylder N, Rooze M, Louryan S: A case with undescended testis, left pelvic kidney and gut malrotation. Surg Radiol Anat. 2005; 27: 382-4.

Accepted after revision: September 22, 2009

nephroptosis. The explanation and the surgical solution seem to be very interesting and impressive.

"For all those, who produce urinary obstruction and those with a beginning dilation, nephropexy still has an efficient justification and may - correctly performed - give much blessings". Nothing needs to be added to this statement of Professor Voelcker from Halle in the year 1911.

\author{
Dr. Martin Hatzinger \\ Klinik fur Urologie \\ Markushospital \\ Frankfurt, Germany
} E-mail:martin.hatzinger@fdk.info 


\section{EDITORIAL COMMENT}

Nephroptosis is a phenomenon that has been known about for centuries. After the first successful surgery for nephroptosis performed by Eugen Hahn (1) surgical therapy of nephroptosis has always been a subject of discussion with up to 200 different surgical variations (2).

In one study, excessive kidney mobility is detected in almost $30 \%$ of healthy subjects without being able to directly connect the known pathologies which were reported in the literature for this phenomenon (3). Can we accept the neptroptosis as a normal variation of the kidney localization?

An interesting paper published in J Endourol has reported about laparoscopic nepropexy for autosomal dominant polycystic kidney diseases for reducing the related pain and giving some tips about the reason and possible pathology (4).

The main goal of the operation is to achieve permanent fixation of the kidney to ensure that the urinary passage remains unobstructed and patient stay pain free during the follow-up. This goal can be achieved using different surgical methods, but the precise etiopathology continues to be unclear, even when the fixation of the kidney due to fat, muscle, fascia and tissue. One issue is clear, that we need long time follow-up data and additional investigation about the newly described techniques with excellent short term results.
One can justifiably describe laparoscopic nephropexy as a suitable, established method for treating symptomatic nephroptosis - and it is one that can be of great therapeutic value to patients when the patients are selected carefully. In this way, laparoscopic nephropexy can help patients become symptom free with an improved quality of life and preserve the kidney from long-term damage.

\section{REFERENCES}

1. Hahn E: Die operative Behandlung der beweglichen Niere durch Fixation. Zbl Chir. 1881; 8: 449-52.

2. Hatzinger M, Langbein S, de la Rosette J, Sohn M, Alken P: Nephropexy in the course of time. Aspects of an historical surgical technique. Urologe A. 2007; 46: 166-9.

3. Thomson WN, Innes JA, Munro JF, Geddes AM, Prescott RJ, Murdoch JM: Renal mobility in women attending a pyelonephritis clinic and in controls. Br J Urol. 1978; 50: 73-5.

4. Casale P, Meyers K, Kaplan B: Follow-up for laparoscopic renal denervation and nephropexy for autosomal dominant polycystic kidney disease-related pain in pediatrics. J Endourol. 2008; 22: 991-3.

\author{
Dr. Dogu Teber \\ Department of Urology \\ SLK-Kliniken Heilbronn \\ Heilbronn, Germany \\ E-mail:dogu.teber@slk-kliniken.de
}

